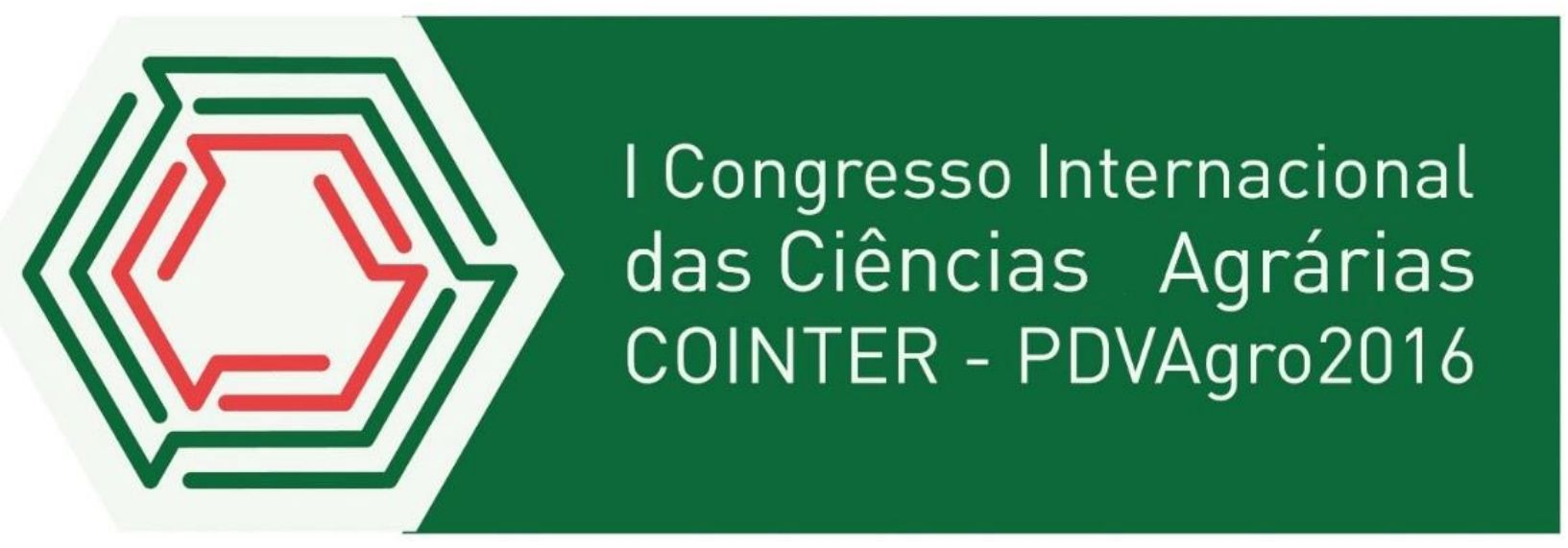

\title{
ANÁLISE DE CONTEÚDO SOBRE O BIOMA CAATINGA EM LIVROS DIDÁTICOS DO ENSINO MÉDIO
}

Apresentação: Pôster

\begin{abstract}
Danilo Dantas da Silva ${ }^{1}$; Laiane Firmo de Lima ${ }^{1}$; Raquel Maria da Conceição ${ }^{1}$; Dalila Regina Mota de $\mathrm{Melo}^{2}$
\end{abstract}

\section{Introdução}

Os livros didáticos constituem o principal recurso didático utilizado nas escolas públicas brasileiras, servindo de material de apoio disponível para alunos e professores, contribuindo para melhoria da prática docente.

Nesse sentido, Cassab e Martins (2008) justifica a importância de uma investigação a respeito da qualidade e adequação deste material à realidade da população local. Essa investigação é particularmente importante considerando que os conteúdos a serem inseridos nos livros didáticos podem reforçar estereótipos e preconceitos sociais (SILVA et al., 2009).

No tocante do Brasil, um país riquíssimo em biodiversidade, deveria se explorar bem essa riqueza em suas localidades específicas, principalmente. A escolha do bioma Caatinga se deu considerando que apesar de ser um bioma exclusivamente brasileiro e de vegetação marcante, este é pouco conhecido dos alunos e dos brasileiros.

Objetivou-se com esse trabalho analisar de forma qualitativa os conteúdos sobre o bioma Caatinga em livros didáticos do ensino médio das escolas públicas de Catolé do Rocha - PB.

\footnotetext{
${ }^{1}$ Licenciatura Plena em Ciências Agrárias, Universidade Estadual da Paraíba, E-mail: danilo20silva@hotmail.com; laianefirmo@gmail.com; raquel21maria@hotmail.com

${ }^{2}$ Doutora em Fitotecnia, Universidade Federal Rural do Semiárido, E-mail: dalilaregina@hotmail.com
} 


\section{Fundamentação Teórica}

O livro didático é um recurso que deve proporcionar o aluno uma compreensão científica, filosófica e estética da sua realidade (VASCONCELLOS; SOUTO, 2003), o que explica sua importância na formação dos alunos e dos seus significados.

No que se refere à análise do livro didático, essa se dá a partir de uma descrição e interpretação dos seus conteúdos, recursos visuais, atividades propostas e recursos complementares (CASSAB; MARTINS, 2008).

A Caatinga é um bioma exclusivamente brasileiro que ocupa cerca de $10 \%$ do território nacional e que possui várias espécies endêmicas, ou seja, que só ocorrem nesta região (LOIOLA et al., 2012). Mesmo diante da importância do bioma, esse é pouco discutido nas salas de aula principalmente nas disciplinas de biologia e geografia do ensino médio (MORAIS et al., 2015).

\section{Metodologia}

A pesquisa foi desenvolvida na Universidade Estadual da Paraíba - Campus IV, município de Catolé do Rocha - PB, no período de agosto a setembro de 2016.

O trabalho teve a metodologia de caráter qualitativo, onde se utilizou como pressupostos teórico-metodológicos elementos da pesquisa bibliográfica e da análise de conteúdo. A pesquisa bibliográfica abrange a leitura, análise e interpretação de livros, mapas e fotografias.

A análise de conteúdo constitui uma metodologia de pesquisa usada para descrever e interpretar o conteúdo de toda classe de documentos e textos. Foram analisados os conteúdos referentes ao bioma Caatinga dos livros didáticos adotados para o $1^{\circ}, 2^{\circ}$ e $3^{\circ}$ anos do ensino médio das escolas públicas do município de Catolé do Rocha - PB.

Com ênfase nos livros de Biologia e Geografia, baseando-se nos critérios do PNLD (Programa Nacional do Livro Didático) para o triênio 2015-2017, foram analisadas seis obras (Tabela 1).

Tabela 1 - Referências bibliográficas dos livros didáticos de Biologia e Geografia do Ensino Médio. Fonte: Própria

\begin{tabular}{cl}
\hline Título & \multicolumn{1}{c}{ Referência } \\
\hline \multirow{2}{*}{ Biologia em Contexto } & AMABIS; MARTHO (2013a). \\
& AMABIS; MARTHO (2013b). \\
& AMABIS; MARTHO (2013c). \\
\hline \multirow{2}{*}{ Geografia Contexto e Redes } & SILVA, et al., (2013a). \\
& SILVA, et al., (2013b). \\
\hline
\end{tabular}




\section{Resultados e Discussões}

Dos livros analisados, a temática Caatinga foi abordada apenas por Amabis e Martho (2013a) e Silva et al., (2013a) - livros de Biologia (Volume 1) e Geografia (Volume 1), respectivamente -, ou seja, no $1^{\circ}$ ano do Ensino Médio em que é trabalhado os conteúdos referentes aos biomas brasileiros e seus domínios morfoclimáticos. Esperávamos que alguma obra dos anos seguintes do ensino médio apresentasse algum texto, exercício ou leitura complementar voltada para o bioma Caatinga para ser feita a relação dos conteúdos curriculares da disciplina com as questões ambientais de ocorrência regional.

Esse fato pode ser consequência da falta de conhecimento sobre o bioma, considerando que a vegetação da Caatinga é uma das menos conhecidas do país (LOIOLA et al., 2012) ou da insuficiente divulgação do conhecimento científico sobre ele (SOUSA et al., 2010). Uma possível justificativa para que o tema não tenha sido apresentado no $2^{\circ}$ e $3^{\circ}$ anos do Ensino Médio seria o fato de já ter sido trabalhado no $1^{\circ}$ ano, sendo dispensável pelos autores uma nova abordagem.

O livro de Biologia (AMABIS; MARTHO, 2013a) traz um pequeno texto sobre a Caatinga, no qual destaca a área de abrangência, os baixos índices pluviométricos, as condições climáticas rigorosas e os ventos fortes e secos que contribuem para aridez da paisagem nos meses secos do ano. Este refere-se à flora da Caatinga como um conjunto de plantas que possuem adaptações características denominadas xeromorfismo, o que atribui características típicas ao bioma. Neste trecho, aspectos biológicos do bioma são abordados, como a flora, que são exemplificados com três espécies de plantas:

Entre as plantas cactáceas, as mais expressivas são o mandacaru (Cereus sp.) e o xiquexique (Pilocereus sp.). Há arbustos e árvores baixas como mimosas, acácias e amburanas (leguminosas). Entre as poucas espécies da caatinga que não perdem as folhas na época seca, destaca-se o juazeiro (Zizyphus joazeiro), uma das plantas mais típicas desse bioma. (AMABIS; MARTHO, 2013a, p. 142).

É evidente, que a vegetação da Caatinga é composta basicamente por arbustos e árvores de baixo ou médio porte e com grande quantidade de plantas espinhosas, como as leguminosas e as cactáceas (ABÍLIO et al., 2010), sendo uma das características mais marcantes do bioma. Por outro lado, nenhuma menção é feita sobre a diversidade da fauna e sobre aspectos ligados a importância econômica e conservação. 
A obra traz ainda um mapa mostrando a ocupação e localização da Caatinga no território brasileiro e uma única fotografia que apresenta uma área de Caatinga com um cacto ao centro e árvores secas ao fundo, talvez como forma de enfatizar o contraste entre o ambiente seco e a biodiversidade do bioma. Para Vasconcelos e Souto (2003), os recursos visuais facilitam a atividade docente e a compreensão do aluno, subsidiando a aprendizagem e fornecendo suporte vital às ideias e informações contidas no livro, merecendo por isso, atenção especial.

O livro de Geografia (SILVA et al., 2013a) aborda o tema Caatinga sob uma perspectiva de domínio morfoclimático das caatingas, caracterizando-a como uma porção semiárida nordestina marcada pela escassez, irregularidade das chuvas e solos pouco profundos.

Apesar de retratarem diversas características do bioma, algumas informações estão ausentes nas obras. Por exemplo, não se discute sobre a população ali inserida, sobre as espécies nativas da região, quais os impactos ambientais ocorridos e o que fazer para conservar o bioma. Podemos observar ainda que a abordagem de outros biomas - Floresta Amazônica, Cerrado e Mata Atlântica - são bem mais abrangentes. Assim, novamente salientamos a necessidade de enfocar nos livros utilizados as questões ambientais de ocorrência regional.

Sobre o termo bioma, as obras apresentam conceitos condizentes:

Pode-se definir bioma como uma área geográfica de ambiente uniforme, caracterizado pelo clima, pelos solos e pela fisiologia de sua vegetação (AMABIS; MARTHO, 2013a, p. 127).

Entendido como um conjunto espacial em que haja uma interação entre os processos ecológicos e as paisagens. Neles, têm-se uma coerência entre diversos elementos da paisagem, como relevo, tipos de solos, formas de vegetação e condições climático-hidrológicas (SILVA et al., 2013a, p. 177).

Almeida (2003) ao analisar livros didáticos de Biologia e Geografia do ensino médio, constatou que os conteúdos referentes ao bioma Caatinga apresentavam-se de forma descritiva e memorística, e que as informações contribuíam para fortalecer a ideia de um ambiente sem desenvolvimento e homogêneo, distante de uma abordagem que permita uma visão socioambiental desse ecossistema.

\section{Conclusão}

As abordagens relacionadas ao bioma Caatinga nos livros didáticos analisados são bastante limitadas, sendo necessário ser trabalhada com mais detalhes devido à importância e exclusividade do bioma. 


\section{Referências Bibliográficas}

AMABIS, J. M.; MARTHO, G. Rua Biologia em Contexto. $1^{a}$ ed. São Paulo: Moderna, 2013a. v. 1.

AMABIS, J. M.; MARTHO, G. Rua Biologia em Contexto. $1^{\text {a }}$ ed. São Paulo: Moderna, 2013b. v. 2.

AMABIS, J. M.; MARTHO, G. Rua Biologia em Contexto. $1^{a}$ ed. São Paulo: Moderna, 2013c. v. 3 .

ABÍllO, F. J. P.; RAMOS, D. S. C; SILVA, D. S. Bioma Caatinga, Meio Ambiente e Educação Ambiental nos Livros Didáticos de Ciências, Biologia e Geografia. In: ABÍLIO, F. J. P. (Org.). Educação Ambiental: formação continuada de professores no Bioma Caatinga. João Pessoa: Editora Universitária/UFPB, 2010. p. 145-169.

ALMEIDA, M. C. V. O ecossistema caatinga nos livros didáticos de Biologia e Geografia do Ensino Médio: perspectivas para sua abordagem. 2003. 94 p. Dissertação (Mestrado em Desenvolvimento e Meio Ambiente). Universidade do Estado do Rio Grande do Norte, Mossoró, 2003.

CASSAB, M.; MARTINS, I. Significações de professores de ciências a respeito do livro didático. Ensaio - pesquisa em educação em ciências, v. 10, n. 1. p. 1-24, 2008.

LOIOLA, M. I. B.; ROQUE, A. A.; OLIVEIRA, A. C. P. Caatinga: Vegetação do semiárido brasileiro. Revista Ecologi@, v. 4. p. 14-19, 2012.

MORAIS, A. R; PEREIRA, G. S.; MARIA, D. L.; QUEIROGA, A. M. F.; MARINHO, M. G. V. Percepção do Bioma Caatinga de alunos do ensino médio da escola estadual professor José Gomes Alves, Patos - PB. In. II Congresso Nacional da Educação, 2015, Campina Grande - PB. Anais do II Congresso Nacional da Educação, 2015.

SILVA, M. S. F.; SOUZA, R. M. O potencial fitogeográfico de Sergipe: uma abordagem a partir das unidades de conservação de uso sustentável. Scientia Plena, v. 5, n. 10. p. 1-11, 2009.

SILVA, A. C.; OLIC. N. B.; LOZANO, R. Geografia: contexto e redes. $1^{\mathrm{a}}$ ed. São Paulo: Moderna, 2013a. v. 1.

SILVA, A. C.; OLIC. N. B.; LOZANO, R. Geografia: contexto e redes. $1^{\text {a }}$ ed. São Paulo: Moderna, 2013b. v. 2.

SILVA, A. C.; OLIC. N. B.; LOZANO, R. Geografia: contexto e redes. $1^{\text {a }}$ ed. São Paulo: Moderna, 2013c. v. 3.

SOUSA, C. M.; HAYASHI, M. C. P. I.; SILVA, M. K. D.; GONÇALVES, W. L. Ciência, comunicação e Caatinga: encontros e desencontros. Diálogos \& Ciência, v. 4, n. 12, p. 65-79, 2010. 
VASCONCELOS, S. D.; SOUTO, E. O livro didático de Ciências no ensino fundamental proposta de critérios para análise do conteúdo zoológico. Ciências \& Educação. v. 9, n. 1, p. 93104, 2003. 